\title{
Correction to: Three-Dimensional \\ Consensus-Based Control \\ of Autonomous UAV Swarm Formations
}

\author{
Tagir Muslimov (D) and Rustem Munasypov
}

\section{Correction to:}

Chapter 5 in: A. Ronzhin and V. Shishlakov (eds.),

Proceedings of 15th International Conference

on Electromechanics and Robotics "Zavalishin's Readings",

Smart Innovation, Systems and Technologies 187,

https://doi.org/10.1007/978-981-15-5580-0_5

The original version of the book was published with incorrect figure 5.2 and equation 5.7 are updated as in below:

$$
\mathbf{h}^{i n c l}=\left(h_{i}^{i n c l}\right)_{i=\overline{1, N}}=\left(-r_{d}-\sqrt{\left(s_{n}^{i}\right)^{2}+\left(s_{e}^{i}\right)^{2}}\left(q_{d} / \sqrt{q_{n}^{2}+q_{e}^{2}}\right)\right)_{i=\overline{1, N}}+\mathbf{F}^{\Delta h},
$$

where $\mathbf{h}^{\text {incl }} \in \mathbb{R}^{N \times 1}$ is the vector of flight altitude commands for the UAV group; $s_{n}^{i}, s_{e}^{i}$ are the coordinates of the vector $\mathbf{s}^{i}=\mathbf{e}_{p}^{i}-\left(\mathbf{e}_{p}^{i} \cdot \mathbf{n}\right) \mathbf{n}$, which in its turn is calculated from the normal vector $\mathbf{n}=\left(\mathbf{q} \times \mathbf{k}^{i}\right) /\left\|\mathbf{q} \times \mathbf{k}^{i}\right\|$ and the ICS UAV position error $\operatorname{vector}_{p}^{i} \triangleq\left[\begin{array}{lll}p_{n}^{i}-r_{n} & p_{e}^{i}-r_{e} & p_{d}^{i}-r_{d}\end{array}\right]^{\mathrm{T}}$; here vector $\left[\begin{array}{lll}p_{n}^{i} & p_{e}^{i} & p_{d}^{i}\end{array}\right]^{\mathrm{T}}$ describes the $i$ th UAV coordinates in the ICS; vector $\mathbf{F}^{\Delta h}$ is determined as in the Eq. (5.5).

The chapter and book have been updated with the changes.

The updated version of this chapter can be found at https://doi.org/10.1007/978-981-15-5580-0_5

(C) The Editor(s) (if applicable) and The Author(s), under exclusive license to 


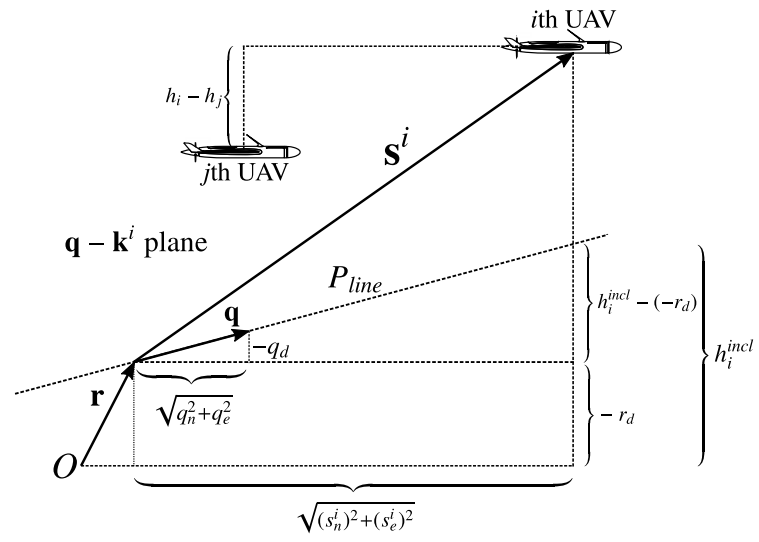

Fig. 5.2 An example of how symbols could be defined for a UAV formation following a descending path. Figure partly adapted from [15] 